\title{
Research Article \\ Benefits of Seismic Isolation for Nuclear Structures Subjected to Severe Earthquake
}

\author{
Rosa Lo Frano \\ DICI, University of Pisa, Pisa, Italy \\ Correspondence should be addressed to Rosa Lo Frano; rosa.lofrano@ing.unipi.it
}

Received 22 March 2018; Revised 9 August 2018; Accepted 23 August 2018; Published 1 October 2018

Academic Editor: Leon Cizelj

Copyright (C) 2018 Rosa Lo Frano. This is an open access article distributed under the Creative Commons Attribution License, which permits unrestricted use, distribution, and reproduction in any medium, provided the original work is properly cited.

\begin{abstract}
The Fukushima accident has reiterated that the seismic safety is a clear necessity in the design of nuclear power plants. To overcome the weaknesses of the plant design, appropriate measures or interventions have thus to be put in place to improve the nuclear safety. In this study, seismic isolation, widely adopted for conventional constructions, is considered as retrofit measure to provide superior performance of plant itself, even when exceptional events occur. In this paper, we numerically investigate the dynamic behaviour of a Small Modular Reactor (SMR) plant subjected to 0.6g PGA; in doing that time-history analysis has been performed assuming the reactor building with and without isolators. For that purpose, a suitable FEM model has been implemented to provide in-structure response spectra at safety relevant locations and subsystem supports. Adequate steel and concrete properties as well as isolators properties, experimentally determined, have been assumed. Results have shown the benefits of seismic isolation for NPP that can so sustain levels of loading beyond the design input and demonstrated that failure of an isolation system cannot occur before failure of the isolated structure. However, the large horizontal displacements of the structure require appropriate considerations in the layout and interfaces for interconnected systems.
\end{abstract}

\section{Introduction}

After the Fukushima accident, all nuclear power plants have been reexamined (stress-test required by the national and international safety authority) in order to verify the capacity of nuclear plants to withstand extreme and rare events, such as earthquakes and tsunamis. The reassessment of plant capacity (goals of stress tests) is especially required when beyond design events occur, as all materials may degrade to some degree and lead to an unsafe state that means loss of integrity and functional capability. To comply with "stress tests" requirements, the robustness of plants is (or needs to be) verified to be confident of the plant integrity and, when it is the case, to introduce improvement measures to restore safety [1].

For a given plant, a deterministic evaluation is therefore required to characterize the behaviour of structures, providing also information on weak point and cliff-edge effect $[2,3]$ if any, especially for

(1) beyond design earthquake;

(2) beyond design flooding;
(3) other extreme external conditions that could jeopardize the plant.

The Fukushima accident [4] has once again reiterated that safety against externally initiator events is a clear necessity in the design of nuclear power plants along with the need to identify new procedures and solutions aimed at reducing the overall core damage frequency.

To overcome the weaknesses of the plant design that emerged during the evolution of the Fukushima accident scenario, appropriate measures or interventions have to be put in place to improve the nuclear safety [5-7]. To identify these improvement measures, key questions to pose are about the priority of structures to be strengthened and how to identify them; if it is possible (or worthwhile) to strengthen them and till what extent; what the available and usable resources are (materials, methods, and techniques) to intervene. For seismic strengthening some options are

(a) local or overall modification of (un)damaged elements (repair, strengthening, or full replacement), considering their stiffness, strength, and /or ductility; 


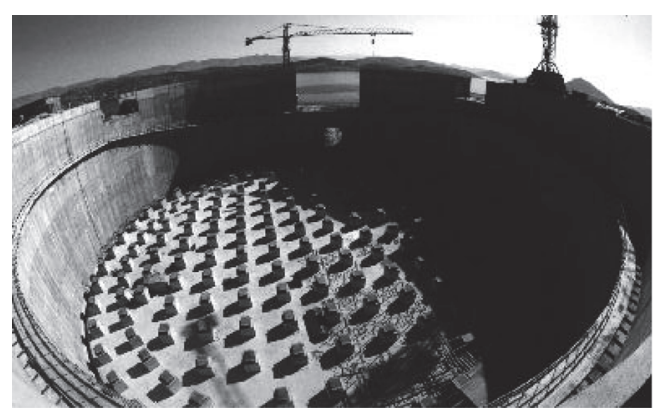

FIGURE 1: Isolated LNG tank (Tajirian, 1990).

(b) addition of new structural elements (e.g., bracings or infill walls) to partially or totally sustain the seismic action;

(c) possible transformation of existing nonstructural elements into structural elements;

(d) introduction of passive protection devices or dissipative bracing or base isolation.

Figure 1 shows a typical installation of seismic isolation devices.

In general, seismic isolation for nuclear structures is not different from that developed and qualified for other industrial and commercial applications; nevertheless, the characterization of the safety margins of seismic isolation devices, as well as the understanding of their failure modes, is of additional importance in nuclear applications.

In the safety analysis described in what follows, seismic isolation is taken into consideration as a measure to improve the plant's capacity even when exceptional events occur; by limiting the inertial forces and vibrations transmitted from the ground to the isolated nuclear facility, it is possible to increase the plant safety margin.

The following sections of this paper address the main aspects of the safety analysis and design of a nuclear plant containment subjected to a Fukushima-like scenario [4] and the comparison between isolated and not isolated safetyrelated nuclear structures. Section 2 introduces the performance expectations for seismic isolators and systems. Section 3 describes the safety assessment of small-medium plant for beyond design basis earthquake (BDBE) and provides details of modelling. Section 4 provides the main dynamic analysis results.

\section{Seismic Isolation Performance Objectives}

To date, many efforts have been spent in studying the performance of the seismic isolation systems [5]. As for the nuclear power plant concerned, the evaluation of strong earthquake motion effects is required as one of the conditions for the design and construction approval of the plant itself. In this context, the possibility of adopting seismic isolation is considered an important means to enhance the reliability and safety of plants, the design of which is site dependent. Seismic isolation has therefore become more and more attractive also in the nuclear field, as the mitigation of the consequences of severe earthquakes (demands) results in an increase of the load bearing capacity (safety margin) of NPP structures themselves. Although the general idea of seismic isolation has been taken into consideration for long time, real practical applications evolved rapidly over the last decades because of

(a) developments of reliable elastomer bearings;

(b) development of reliable analytical methods for the prediction of the dynamic response of structures;

(c) possibility of validating the developed analytical models and demonstrating the performance characteristics of structure by means of shaking table test.

In addition, there are attempts to use seismic isolation, applied for the civil structures such as hospitals and bridges [8] to mitigate the damaging effects of earthquakes, in surface or near surface mounted nuclear structures to increase safety (reduction of seismic risk). An important study is conducted by Nagarajaiah and Sun, 2000 [9]. They analyzed the performance of base isolated USC hospital building during the Northridge earthquake and observed a reduction to nearly $50 \%$ of the peak acceleration at the roof compared to the peak ground acceleration (PGA) and also that the structure remained in the elastic range. Indeed this result would not have been possible for a fixed base structure.

Whittaker et al. 2014 documented some of the progress in developing knowledge and tools to aid in the implementation of seismic isolation systems in nuclear power plants. They provide also technical information on the performance expectations identified in the NUREG and in the ASCE, for seismic isolation systems.

Huang et al. $2011 \mathrm{a}, \mathrm{b}[10,11]$ demonstrated that the same benefits (reduction of risk and increase of safety) are possible for nuclear power plant structures. This is possible because the seismic isolation relies on a dynamic response modification technology, obtained through the installation between the basemat and soil of a horizontally flexible and vertically stiff device (the isolator).

Finally it is worth noting that, in recent years, seismic isolation has been used to design and construct the nuclear facility structures at Cruas and Koeberg (sites with moderate seismicity) in late 1970s and early 1980s, while in the USA two seismically isolated reactor designs, PRISM and SAFR, were developed in early 1990s. The former were adopted by designing 1800 neoprene pads measuring 50x50x6.5 cm and 2000 pads measuring 70x70x10 cm, respectively.

For sites with higher seismicity, Jolivet and Richli 1977 [12] discussed the adoption of sliding plates guaranteeing a friction factor of 0.2 . Besides, liquid metal reactors, such as ALMR, ALFRED, or ASTRDID, were envisaged by designing seismic isolation to cope with issues due to the large inertia force $[13,14]$.

2.1. Isolator Objectives. Isolators (having isolation capacity only or mainly in the horizontal plane) are assumed to be installed in a near horizontal plane beneath the basemat and surrounded by a moat; in this space the isolated structure can move freely in the event of earthquake shaking [15].

The appeal of isolators resides in the combination of a high stiffness in the vertical direction, obtained in the case of rubber bearing through thin steel shims, and a high flexibility in the orthogonal planes, own property of the material. 


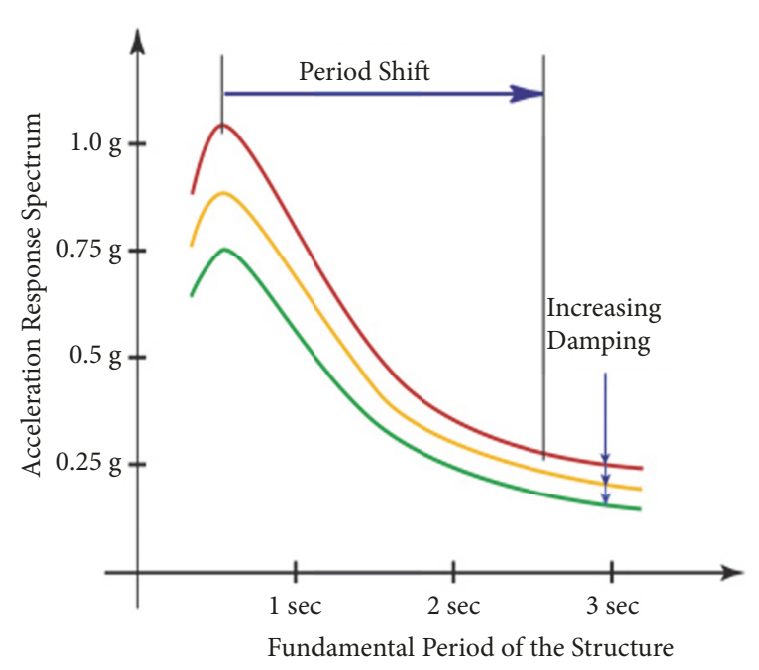

(a)

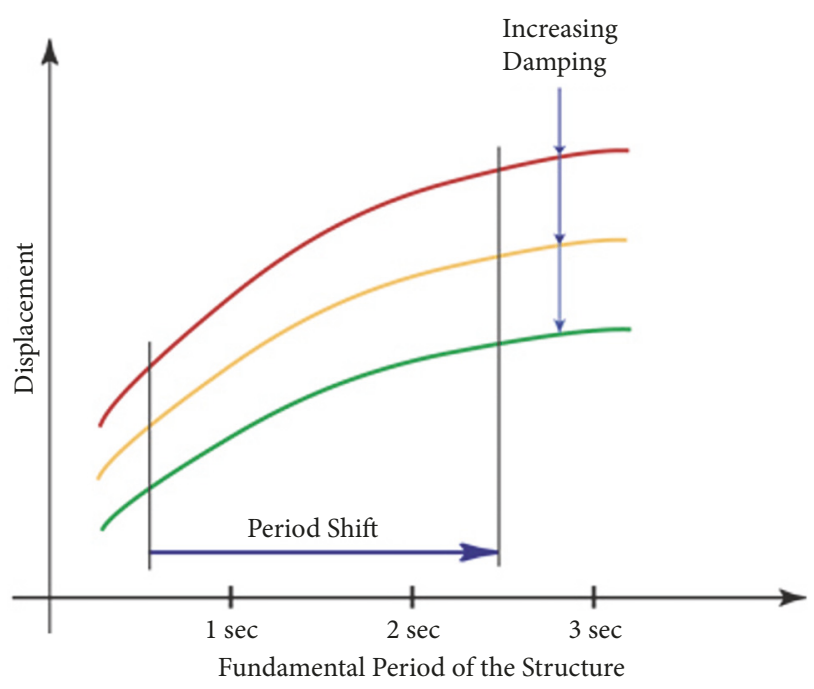

(b)

FIGURE 2: Plots illustrating isolators' performances (effects of lengthening of structure period).

By lengthening the fundamental time-period of the superstructure (to a value higher than that of earthquake), they damp the seismic energy (Figure 2): forces transferred to the plant structures are drastically reduced and so is the acceleration. These characteristics make seismic isolation attractive for nuclear power plant [8]. Figure 2(a) represents the reduction of the acceleration with increase of the period of structure, while (b) shows the corresponding displacement trend. This latter must comply with moat and affects the selection of isolators.

Seismic isolation is treated as a civil/structural subsystem of a nuclear power plant whose risk--informed design is governed by the performance objectives defined in the ASCE 2005 [16] together with ASCE 2017 [17]. These standards, relevant to the seismic analysis and design of nuclear structures, define the objective to achieve (i.e., the annual target performance).

For seismic design, as prescribed in Sect. 1.3 of ASCE 43, performance expectations [18] are, namely,

(i) less than $1 \%$ probability of unacceptable performance against $100 \%$ design basis earthquake (DBE) shaking;

(ii) less than $10 \%$ probability of unacceptable performance against $150 \%$ DBE shaking (or beyond design basis earthquake (BDBE));

(iii) seismic demand at the isolated structure calculated at the $80^{\text {th }}$ percentile for $\mathrm{DBE}$ and $90^{\text {th }}$ percentile for BDBE;

(iv) introduction of a physical stop or perimeter damper (at $90 \%$ displacement demand at $1.5 \mathrm{xDBE}$ input). The adoption of perimeter damper solution, proposed also by Forni et al. 2009 [19], will absorb possible loads derived from the impact of isolated nuclear structure with surrounding moat in the case of earthquake magnitude exceeding the assumed design value.
2.2. Benefits and Challenges of Seismic Isolation for NPP. Seismic isolation is highly attractive for the nuclear industry because, in respect to the conventional design strategy, based on the strengthening of structures and components, it allows reducing the threats/hazards caused by the external events. For seismically isolated plants, the safety characteristics still depend on safety considerations. It is so accepted that isolators can be made with large margins beyond the design basis earthquake such that failures would happen in the superstructure before elastomer bearings fail. The main general benefits are

(i) potential reduction of the spectral demand by a factor of more than $10 \%$, increasing the fundamental period from 0.1 to 2 seconds (isolated construction); this factor could vary (increase or decrease) in some cases.

(ii) enhancement of the safety and reliability of nuclear power plants to regain public acceptance;

(iii) facilitating the decoupling of the reactor design from the balance of plant one and licensing which is regional in nature;

(iv) requiring lesser degree of seismic qualification for the plant secondary components and systems;

(v) possible standardization of the plant design regardless of seismic conditions;

(vi) reduction of capital costs as a consequence of standardization.

Challenges to face are due mainly to the large displacements of seismic isolation device and to the long-term durability under sustained loading conditions. Further aspects refer to instability and secondary effects due to the impact of the superstructure with surrounding structure for beyond design earthquake conditions. 


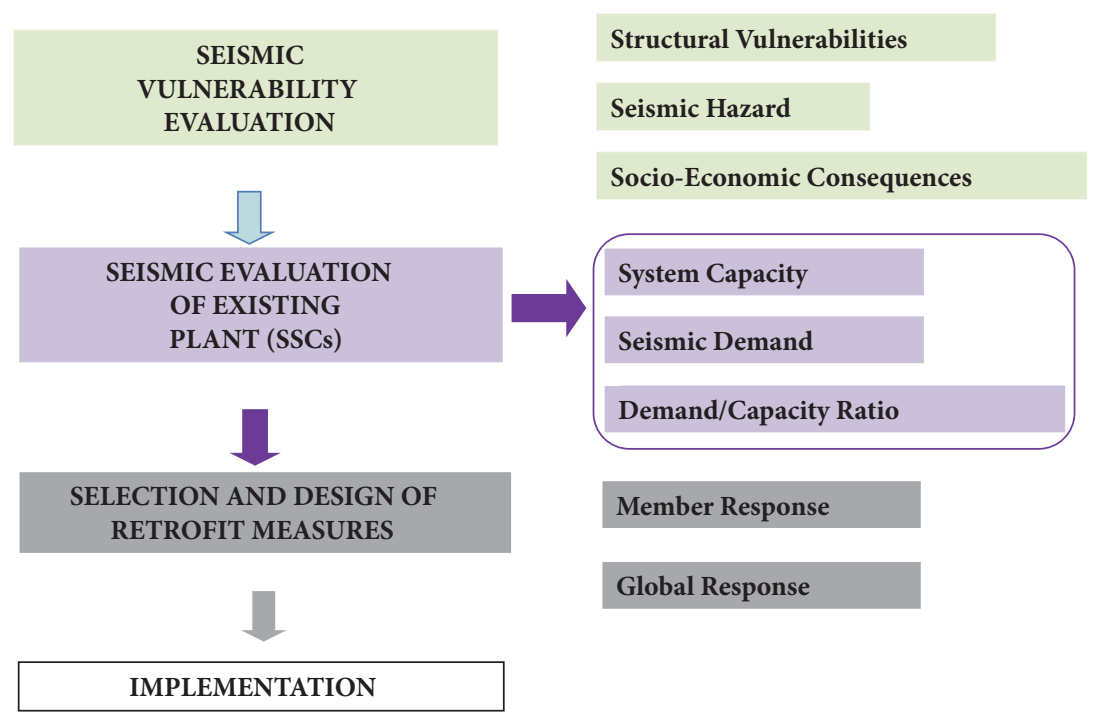

FIGURE 3: Methodology to evaluate actual performance of nuclear structures.

\section{BDBE Safety Assessment: Methodology and Analysis}

In this section, we describe the main aspects of the safety analysis on a SMR, looking like the IRIS reactor [20] subjected to a Fukushima-like scenario [4], and the comparison between isolated and not isolated safety-related nuclear structures.

The selected SMR, whose safety assessment is the case study in this paper, represents the latest evolution of the LWR technology for a number of new and innovative components' design solutions. The information relating to its design and layout and materials is gathered in Carelli et al. 2004 [21]: a more realistic investigation of the plant safety margin is therefore possible minimizing uncertainties. Specifically, in the present study we focus on the investigation of the containment building that is the last defence in depth barrier against release of radioactivity to the environment (plant description is also provided by Forni 2009 and Lo Frano 2010 a, b $[22,23])$.

Figure 3 shows a general breakdown for the safety assessment of NPP components with major subsets: as illustrated in the flow chart, the structural performance is dependent on the risk assessment, understanding of dominant process (demand under the postulated event), and actions/effects induced on the safety relevant equipment.

Information obtained from the global response of plant or member response, in particular the capacity to demand ratio, will allow determining if containment building is able to withstand extreme environment conditions. Otherwise, mitigation measures, restoration methods and practices, and possible change in design shall be implemented.

On attempting to evaluate the safety margin, technical issues characterizing the methodology, somehow common, emerge. A prioritization of components, based on the degree of severity (direct or indirect consequences), has to be performed. In doing that, the containment building that is a key safety system of a NPP is investigated. Moreover, since it is prone to suffer deterioration and damage during $\mathrm{BDBE}$, in this study, we considered the seismic isolation as possible design improvement (retrofit measure).

The seismic isolation, by decoupling the containment building from the soil, will allow improving the capacity of structure and enlarging the safety margin of the plant.

3.1. Seismic Safety Assessment. The primary objective of this study is the characterization of seismic demand of containment system in conventional and seismic-protected NPP construction.

The proposed methodology aims first to provide SMR with an effective seismic isolation system; this is done by setting firstly the isolation frequency (to be lower than the plant one) to comply with the moat and the spectral demand reduction achievable: the isolation frequency $(\omega)$ we have chosen is $0.5 \mathrm{~Hz}$, which represents a good compromise between the acceleration reduction and the displacement increase. Based on that, we calculated the maximum spectral displacement for an earthquake peak ground acceleration (PGA) at 5\% damping as

$$
S_{d}=\frac{S_{a} \times g}{\omega^{2}} .
$$

In (1), $S_{d}$ and $S_{a}$ are, respectively, the spectral displacement and the spectral acceleration. Afterwards, given the total mass of the plant, the number of isolators $\left(\mathrm{N}_{\mathrm{is}}\right)$ based on their own properties (e.g., damping and stiffness) is calculated as [23]

$$
\mathrm{N}_{\mathrm{is}}=\frac{(2 \pi \mathrm{f}) \times \mathrm{M}_{\mathrm{AB}}}{\mathrm{K}_{\mathrm{AB}_{\mathrm{i}}}}
$$

where

$$
\mathrm{K}_{\mathrm{AB}}=\mathrm{M}_{\mathrm{AB}} \times 4 \times \pi^{2} \times \mathrm{f}^{2} .
$$




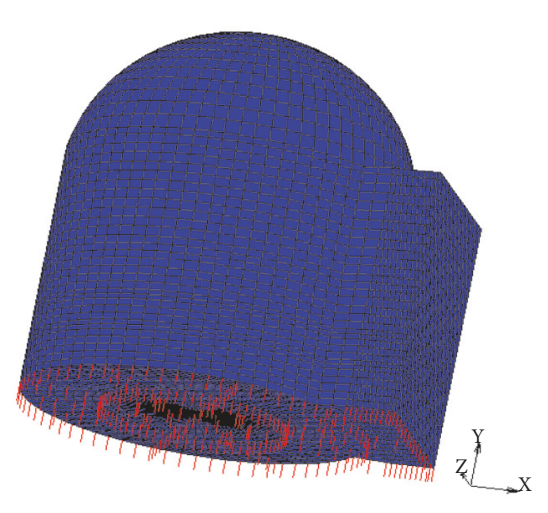

(a)

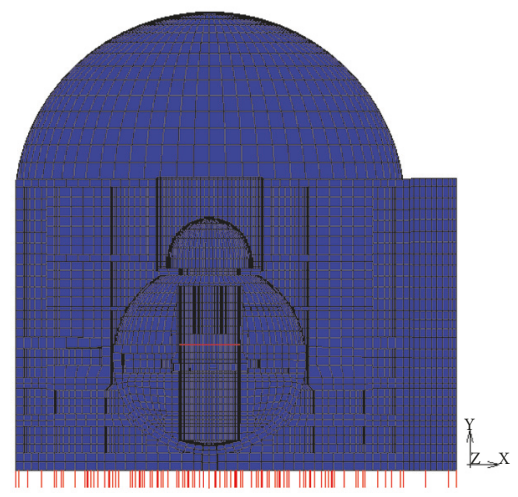

(b)

FIgURE 4: Isolated CB model: view (a) and section (b). In this latter RPV (-9 m below the ground) is represented by the red ties inside containment system.

In the above formulas, $\mathrm{M}_{\mathrm{AB}}$ is the total mass, $\mathrm{K}_{\mathrm{AB}}$ is the global stiffness, and $\mathrm{f}$ is the isolation frequency. For $2 \mathrm{sec}$ period and $\mathrm{M}_{\mathrm{AB}}$ of $8 \cdot 10^{7} \mathrm{~kg}$, to effectively isolate the considered SMR, they require, e.g., 267 isolators of about $3 \mathrm{kN} / \mathrm{mm}$ each.

3.2. FEM Modelling. To judge the utility of seismic isolation for SMR applications, response- (time-) history analysis is performed since it provides more realistic representation of plant performances (deterministic approach, DSA). For this purpose, a 3D Finite Element Model (FEM) of the isolated containment building with its main internal structures (Figure 4) was implemented by means of MSC@MARC code [24] to provide in-structure response spectra at safety relevant locations and subsystem supports. The modelling process required the setting up of appropriate meshes assembled with suitable elements, like the three-dimensional 8-noded solid elements and iso-parametric ones, available in the used FEM code. The nodal point of each element has three translational degrees of freedom about $\mathrm{x}^{-}, \mathrm{y}^{-}$, and $\mathrm{z}$-axis and three rotational degrees of freedom about $\mathrm{x}^{-}, \mathrm{y}^{-}$, and $\mathrm{z}$-axis.

The containment building has $2 \mathrm{~m}$ walls and it is partially embedded $(-20 \mathrm{~m}$ below the ground) with a flat planar basemat to avoid vertical deflection and/or settlement of the foundation and undesirable redistribution of gravity loads. The containment building height above ground is $+33 \mathrm{~m}$.

The basemat and the foundation are hence be sufficiently stiff in the vertical direction to engage all isolators in resisting gravity load effects. The nonstructural components, such as interior partitions or water inventory, that did not add significant contribution to the dynamic response, were considered only in terms of effective mass and initial stiffness so as to represent adequately the dynamic response of the plant. Some internal structures (e.g., RPV and SGs) are represented as lumped masses distributed at appropriately chosen locations to reduce the calculation time.

Damping values for internal components are 5 and $7 \%$ of critical damping, respectively, for welded steel and for reinforced concrete structures.

Based on the overall of mass of the containment building, it was possible to identify an appropriate arrangement of isolators: the alignment of the centre of gravity with the centre of rigidity was also verified to avoid/minimize torsional effects caused by an eccentric isolators' configuration.

Figure 4 shows also the simplified model of seismic isolation adopted for the analysis, which is made up of ensemble of springs and dampers arranged in a complex plane pattern. The formers are sufficiently flexible to impose the extensive participation of a first mode (Table 1) with a long period and to make higher mode responses insignificant.

Isolators are herein qualitatively represented by means of straight lines (red lines in Figure 4(a)) positioned at various points between the soil and the superstructure: threedimensional modelling of isolation is so obtained because of the combination of base horizontal and vertical isolation components. Furthermore, to meet safety requirements and eliminate local deformations at the isolators' pads, clamp restraint is assumed in the analysis. Vertical load bearing and stability were also verified taking into account the maximum values of dead load and live load, and earthquake load associated with the BDBE shaking.

In the simulations, the equivalent characteristics of isolators (three-dimensional systems with horizontal and vertical isolations provided in one single interface) are expressed through the effective stiffness and effective damping of the device [25]: best-estimate mechanical properties, such as horizontal and vertical equivalent stiffness and damping, are used. These properties, which were experimentally determined by testing SI-H 500/50 prototypes, are presented in the following subsection. Finally, the iso-elastic model used to represent isolators is also improved by taking into account the influence of the ratio between the equivalent period and superstructure period.

3.2.1. SI-H 500/50 Experimental Characterization. Validation of analytical model of isolator is based on the evaluation of physical phenomena and dynamic responses of rubber bearing [23]. To do that, several SI-H 500/50 specimens of 0.5 $\mathrm{m}$ in diameter and $0.178 \mathrm{~m}$ in height were tested (Figure 5).

Static and dynamic behaviour as well as ultimate bearing capacity of isolators' prototype were investigated for DBE and 


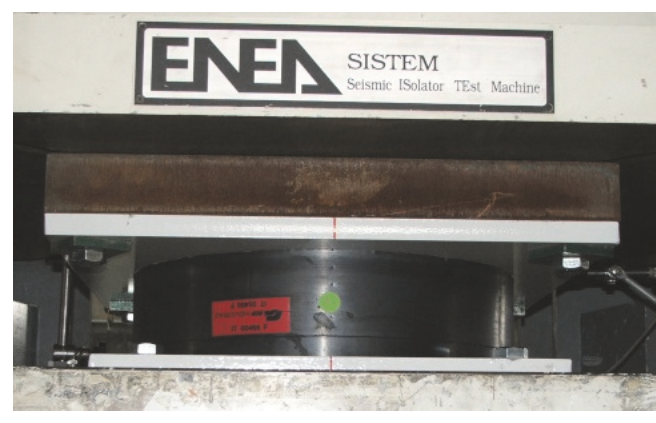

(a)

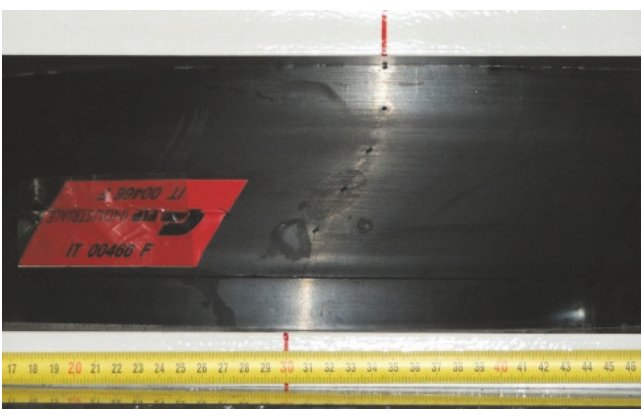

(b)

FIGURE 5: SI-H 500/50 prototype mounted on a roller slide (SISTEM machine) (a) and prototype undergoing 300\% shear strain test (courtesy of ENEA) (b).

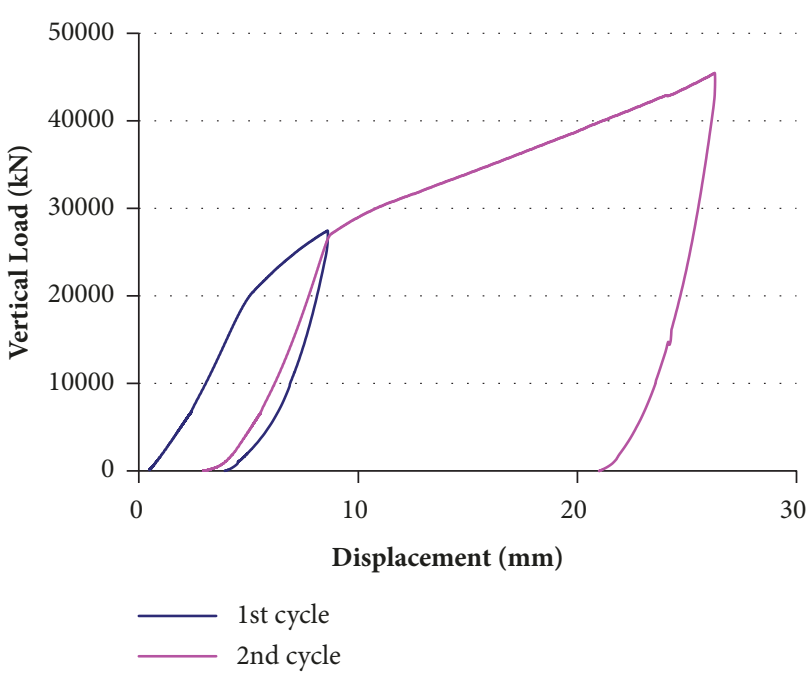

(a)

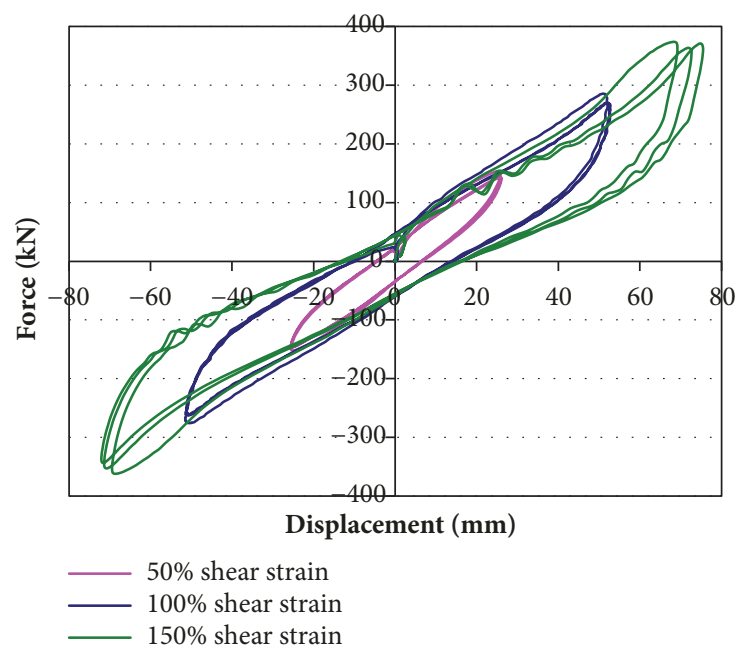

(b)

FIGURE 6: Static and dynamic behaviour of specimen under vertical (a) and horizontal force (b) for different shear strain.

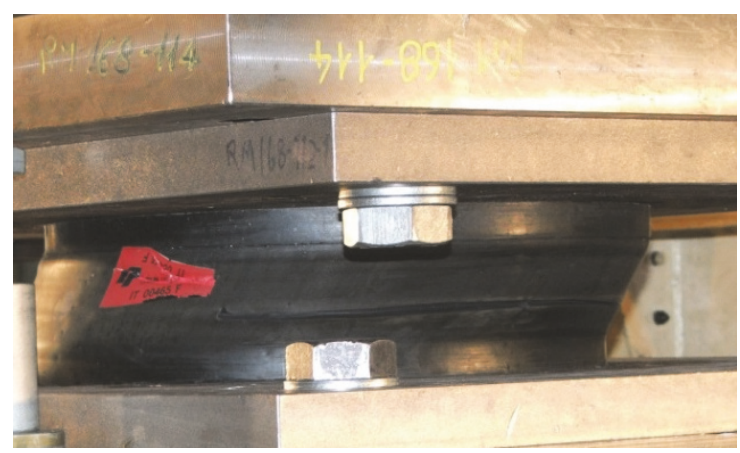

FIGURE 7: Damaged SI-H 500/50 prototype undergoing 350\% shear strain test (courtesy of ENEA).

BDBE conditions. For each specimen, quasi-static horizontal stiffness tests, sinusoidal tests, etc. were executed to determine the stiffness and damping at $100 \%$ shear strain with coexisting gravity/dead weight load and earthquake-induced axial forces. Figure 6 shows a prototype mounted on a roller slide (SISTEM machine) and a prototype undergoing 300\% shear strain test. Table 1 provides the dynamic properties, namely, the vertical stiffness $\left(\mathrm{k}_{\mathrm{v}}\right)$, the horizontal $\left(\mathrm{k}_{\mathrm{o}}\right)$ stiffness, and the damping $(\xi)$ obtained from test execution. As to $\xi$, since it varies from $10 \%$ to $20 \%$ (see Table 1 ), minimum damping value (conservative) was assumed in the simulation performed.

Signs of damage on the tested device appeared at 350\% shear strain: failure was caused to the partial detachment of an internal plate. Nevertheless the prototype showed the capability to withstand the vertical load and to maintain at least a part of its original stiffness (Figure 7).

\section{Dynamic Response}

Firstly, modal analysis was performed to verify that the envisaged seismic isolation plant design objectives are reachable. Frequencies for isolated and not isolated plant are provided in Table 2. The comparison of these frequencies confirms that 


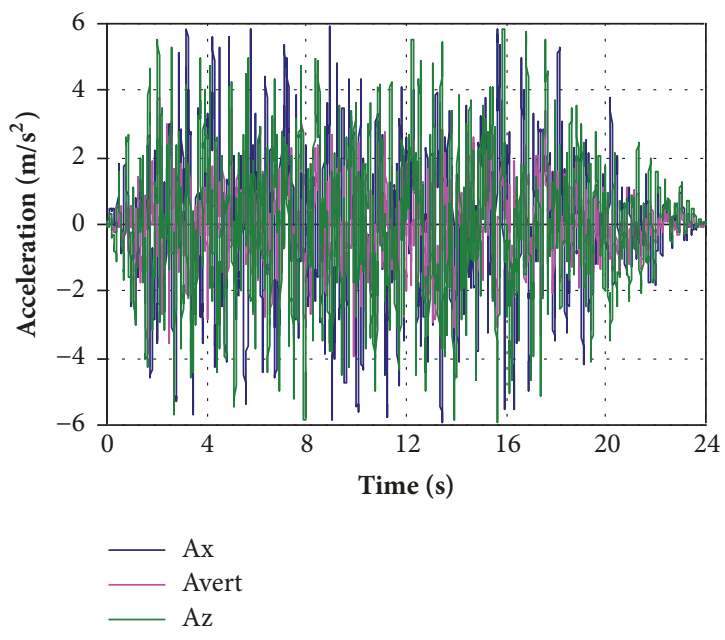

(a)

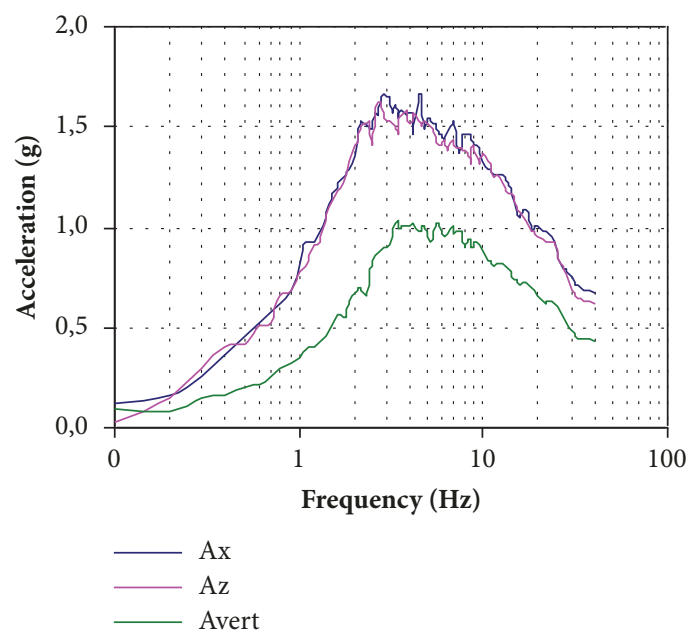

(b)

Figure 8: (a) BDBE ATHs and (b) response spectra.

TABLE 1: Dynamic properties of SI-H 500/50 prototypes.

\begin{tabular}{lccr}
\hline Device id & $\mathrm{k}_{\mathrm{v}}[\mathrm{kN} / \mathrm{mm}]$ & $\mathrm{k}_{\mathrm{o}}[\mathrm{N} / \mathrm{mm}]$ & $\xi[\%]$ \\
\hline IT00462F & 4200 & $4500-4600$ & $10-12$ \\
IT00464F & 4000 & $4500-12000$ & $10-16$ \\
IT00465F & 4200 & $4500-4700$ & $19-11$ \\
IT00466F & 4000 & $4500-14000$ & $10-16$ \\
\hline
\end{tabular}

the design objective is reached. Since the first mode of the superstructure is comparable to a pure horizontal translation, the adopted method of calculation to represent isolation systems can be used.

Transient analysis was afterward carried out by adopting "generated" acceleration time histories (ATHs) of 0.6 g PGA: for this study, all the three components of earthquake motion, which are statistically independent of each other, are applied simultaneously. Consequently, the maximum response of structures is directly obtained from the algebraic summation at each time step and automatically calculated by the FEM code.

ATHs (Figure 8) are calculated according to the NRC R.G. 1.60 requirements and are compatible with the given freefield spectra of $5 \%$ critical damping for the assumed rock soil condition. The vertical acceleration component, namely, $\mathrm{A}_{\mathrm{v}}$, is taken equal to $2 / 3$ the horizontal component in the entire frequency range [26]. For the present BDBE assessment, the total duration of the artificial ground motion is $24 \mathrm{~s}$; this duration is long enough to provide adequate representation of Fourier components also at low frequency. The BDBE ground motion has magnification factor two with respect to DBE. Figure 8 shows that the highest spectral acceleration is in the range $2-9 \mathrm{~Hz}$; in consideration of that, the benefits gained adopting a seismic isolation frequency lower than $1.5 \mathrm{~Hz}$ appear evident.

Nonlinear action is permitted in the structure for all levels of shaking. Lagrangian formulation was assumed to deal with geometric nonlinearity while Newton-Raphson method was assumed for a stable numerical solution. Indeed appropriate values for the elastic limit of concrete and steel were imposed.

The FE solution is progressed through time in step-bystep dynamics, taking into account the velocity and acceleration response in addition to its pure force-displacement behaviour. Finally, it is worth noting that, in the performed analysis, the effects of soil-structure interaction for rock soil condition are small and can be neglected.

4.1. Transient Analysis Results. Analyzing the results obtained from the transient analysis, it appears that the horizontal response of the structure is predominantly influenced by the stiffness of the isolation system: horizontal acceleration has the same values along the containment building regardless of the location of the internal structures. For base isolated containment building the floor response spectra are substantially lower than those obtained for the fixed base structure: worth remarking is that horizontal seismic responses do not vary with the height of the structure, as shown in Figure 9.

Figure 10 shows, e.g., the response spectra at the RPV skirt restraints compared with that for the fixed base structure. A substantial reduction of seismic responses is noted with a decrease of the horizontal acceleration of $30 \%$. The safety margin increases accordingly. The same benefit was not achieved for the vertical component of acceleration, which instead shows an amplification of more than twice the PGA at the apex of the dome of containment building. At the restraints of the RPV skirt, this amplification is not very evident due to the partial embedment of the SMR. 
TABLE 2: Frequency and eigenmode.

\begin{tabular}{|c|c|c|c|c|}
\hline Mode & $F_{n o t}$ is $[H z]$ & Modal shape & $F_{i s}[H z]$ & Modal shape \\
\hline 1 & 5.91 & $1^{\text {st } ~ " c a n t i l e v e r " ~ m o d e ~ i n ~} \mathrm{z}$ direction & 0.497 & $1^{\text {st } ~ " c a n t i l e v e r " ~ m o d e ~ i n ~} \mathrm{z}$ direction \\
\hline 2 & 6.24 & $1^{\text {st } ~ " c a n t i l e v e r " ~ m o d e ~ i n ~} \mathrm{x}$ direction & 0.498 & $1^{\text {st } ~ " c a n t i l e v e r " ~ m o d e ~ i n ~} \mathrm{x}$ direction \\
\hline 3 & 10.09 & $2^{\text {nd }}$ "cantilever" mode in $\mathrm{x}$ direction & 1.386 & Torsion around y axis \\
\hline 4 & 12.14 & $2^{\text {nd }}$ "cantilever" mode in $\mathrm{z}$ direction & 6.21 & $2^{\text {nd }}$ "cantilever" mode in $\mathrm{x}$ direction \\
\hline 5 & 12.31 & Torsion around $\mathrm{z}$ axis & 6.89 & $2^{\text {nd }}$ "cantilever" mode in $\mathrm{z}$ direction \\
\hline 6 & 13.49 & Vertical & 10.19 & Torsion around $\mathrm{z}$ axis \\
\hline 7 & 14.45 & Vertical & 13.08 & Vertical \\
\hline 8 & 14.45 & Shell bending mode around y axis & 13.50 & Vertical \\
\hline 9 & 15.05 & Shell bending mode around y axis & 13.86 & Shell Bending mode around y axis \\
\hline 10 & 15.22 & Shell Bending mode around the $y$-axis & 14.83 & Shell Bending mode around the $y$-axis \\
\hline
\end{tabular}
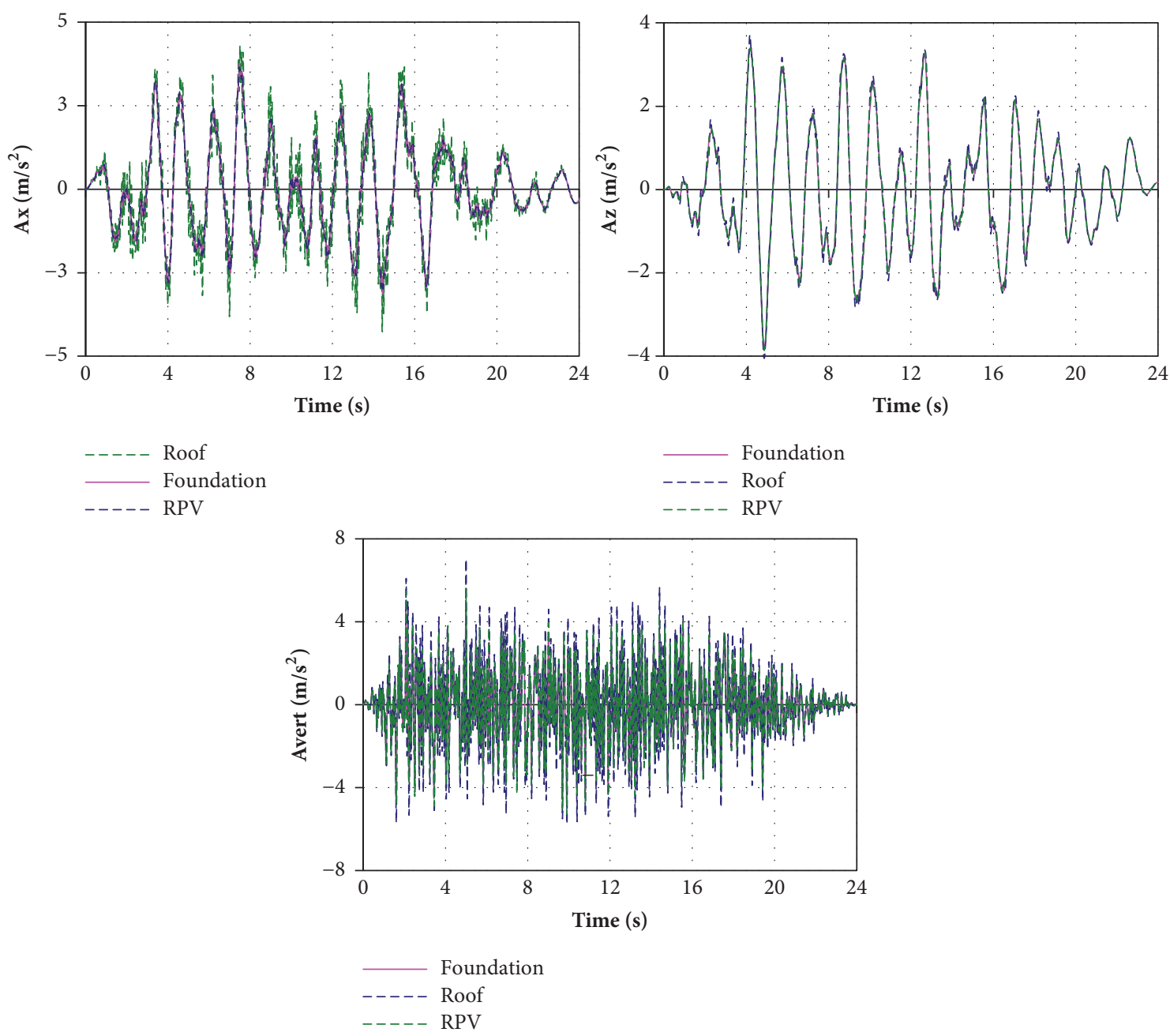

FIGURE 9: Acceleration trend at different elevations along the isolated containment building.

The containment building was demonstrated to have sufficiently uniform lateral resistance to avoid deformations which invalidate the hypothesis that the superstructure cannot be deformed ("rigid body" behaviour).

The horizontal relative displacement at the roof of the containment building/structure is plotted in Figure 11 and compared with that of the fixed base structure. The displacement of the isolated structure is $175 \mathrm{~mm}$ to $200 \mathrm{~mm}$, higher than the displacement of the fixed base structure. Such increased displacement, which is a distinctive feature of the isolated structure, will however require special considerations for interconnected systems, such as the steam mains and other pipes connected to the $\mathrm{BOP}$.

Furthermore, to avoid impact of isolated SMR with surrounding structure the plant-moat clearance shall be higher than $250 \mathrm{~mm}$. 


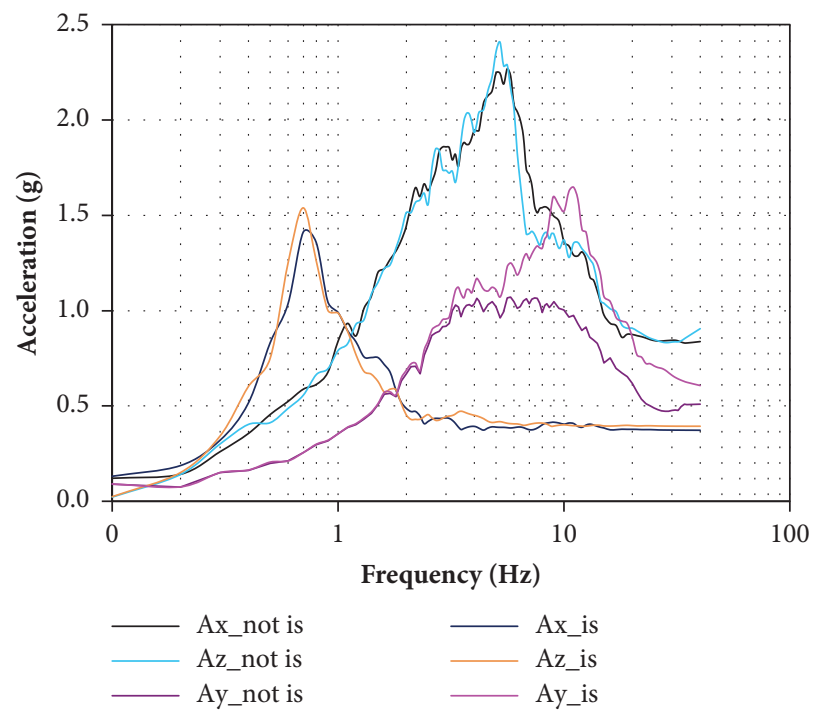

FIGURE 10: Response spectra comparison.

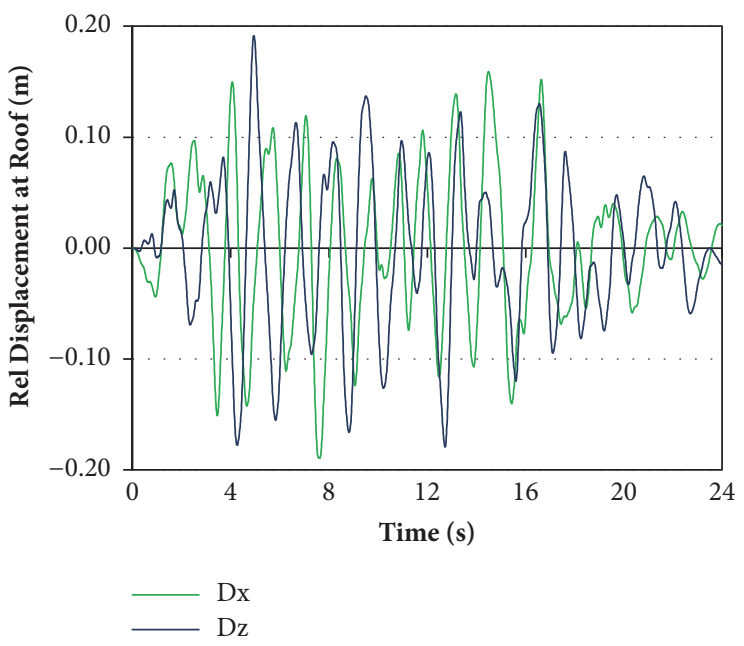

(a)

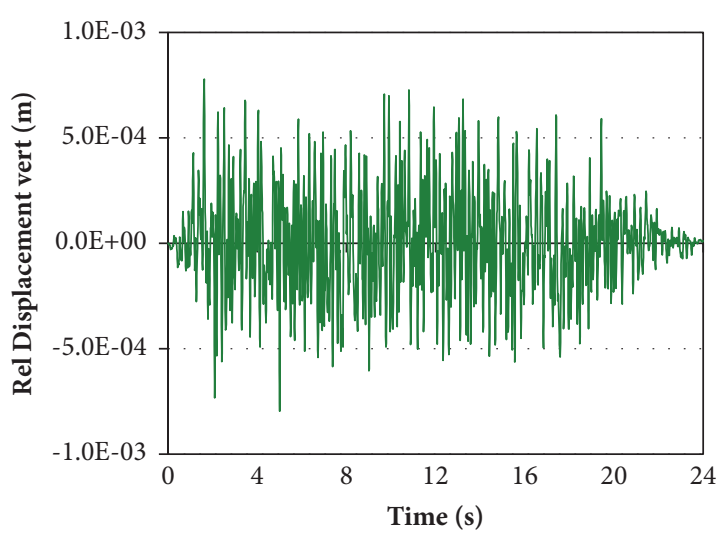

(b)

FIGURE 11: Relative displacements behaviour at roof elevation.

At BDBE level, isolators are subjected to shear strains of 90\%; nevertheless such devices were demonstrated to sustain shear strains in excess of 300\% (see Figure 5(b)) without compromising the bearing capacity or undergoing buckling [2729].

Inertia force decreases along with the acceleration; accordingly, Von Mises stress remained in the elastic field.

Figure 12 shows the stress distribution into the RPV structure. As it is possible to observe, the maximum stress value is about $27 \mathrm{MPa}$, well below the limit value. This confirms the benefit of seismic isolation strategy in increasing the safety margin of the nuclear facility.

\section{Summary}

The safety assessment of an innovative SMR subjected to $0.6 \mathrm{~g}$ PGA was performed with FEM code taking into account appropriate modelling parameters and suitable material properties; those of isolators have been experimentally determined.

Results have shown that seismic retrofitting, by adopting seismic isolation, was demonstrated to be advantageous for NPP that can, in this way, sustain levels of loading beyond any possible seismic input. In addition, they demonstrated that failure of an isolation system cannot occur before failure of the isolated structure.

Isolation devices reduce only horizontal acceleration and floor response spectra drastically; therefore, seismic requirements (demands) of structures, in the frequency range 2-33 $\mathrm{Hz}$, are substantially lower. On the contrary, the horizontal relative displacements increased up to $200 \mathrm{~mm}$ : special considerations shall be put in the design of moat and interconnected systems. 


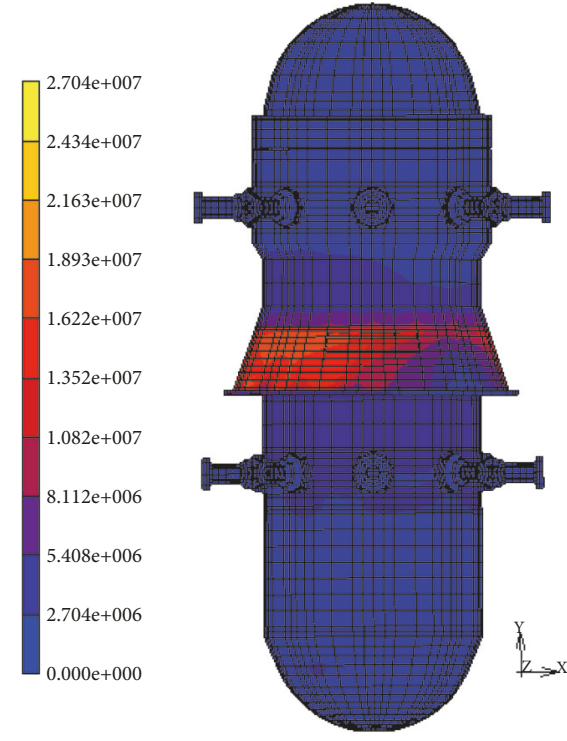

Figure 12: Von Mises stress in the RPV housed in the isolated containment building.

Finally, to benefit from isolators' advantages, a common basemat should be provided.

\section{Data Availability}

(1) The acceleration data along with the FEM frequency behaviour and input spectrum used to support the findings of this study are included within the article. (2) The dynamic properties of SI-H 500/50 prototypes used to support the findings of this study are included within the article. (3) The data referring to the $2 \%$ isolator failure and isolation buckling used to support the findings of this study are available from the corresponding author upon request.

\section{Conflicts of Interest}

The author declares that they have no conflicts of interest.

\section{Acknowledgments}

The author would like to thank ENEA for kindly providing HRDB experimental results. The testing activity was financed by MiSE in the framework of 2010 AdP. The author would like to thank and remember especially prof. G. Forasassi for his constant unfailing support, precious contribution given over the years, and valuable teaching.

\section{References}

[1] R. Lo Frano, G. Forasassi, A. Poggianti, and M. Forni, "Seismic safety margin of an isolated SMR reactor under severe earthquake," in Proceedings of the ASME 2011 Small Modular Reactors Symposium, vol. 67, Washington DC, Wash, USA, September 2011.

[2] IAEA SSG-2, Deterministic Safety Analysis for Nuclear Power Plants,
[3] IAEA NS-G-2.13, Evaluation of seismic safety for existing nuclear installations, 2009.

[4] IAEA, The Fukushima Daichii Accident, GC(59)/14, report by the Director General, 2015.

[5] F. F. Tajirian, J. M. Kelly, and I. D. Aiken, "Seismic isolation for advanced nuclear power stations," Earthquake Spectra, vol. 6, no. 2, pp. 371-401, 1990.

[6] J.-C. Postollec, Les foundations antisismiques de la Centrale Nucleare de Cruas-Meysse, notes du service etude geni civil d'EDF-REAM, 1983.

[7] R. Lo Frano and G. Forasassi, "Preliminary evaluation of the reliability of Gen II or III reactors in BDBE conditions," in Proceedings of 20th ICONE, vol. 3, Anaheim, Calif, USA, 2012.

[8] J. M. Kelly and D. A. Konstantinidis, Mechanics of Rubber Bearings for Seismic and Vibration Isolation, Wiley, 2011.

[9] S. Nagarajaiah and S. Xiaohong, "Response of base-isolated USC hospital building in Northridge earthquake," Journal of Structural Engineering, vol. 126, no. 10, pp. 1177-1186, 2000.

[10] Y.-N. Huang, A. S. Whittaker, and N. Luco, "A probabilistic seismic risk assessment procedure for nuclear power plants: (I) Methodology," Nuclear Engineering and Design, vol. 241, no. 9, pp. 3996-4003, 2011.

[11] Y. Huang, A. S. Whittaker, and N. Luco, "A probabilistic seismic risk assessment procedure for nuclear power plants: (II) Application," Nuclear Engineering and Design, vol. 241, pp. 4004-4011, 2011.

[12] J. Jolivet and M. H. Richli, Aseismic foundation system for $n u-$ clear power stations, SMiRT-4, Paper K.9/2, San Francisco, Calif, USA, 1977.

[13] F. F. Tajirian and M. R. Patel, "Response of seismic isolated facilities, a parametric study of the ALMR," in Proceedings of the 12th SMiRT Conference, Stuttgart, Germany, August 1993.

[14] T. Fujita, "Progress of applications," in Proceedings of the Japan, Int. Post-SMiRT Conference Seminar on Seismic Isolation, Passive Energy Dissipation and Active Control of Seismic Vibrations of Structures, Taormina, Italy, August 1997.

[15] A. S. Whittaker, M. Kumar, and M. Kumar, "Seismic isolation of nuclear power plants," Nuclear Engineering and Technology, vol. 46, no. 5, pp. 569-580, 2014.

[16] ASCE, Seismic Design Criteria for Structures, Systems and Components in Nuclear Facilities, ASCE 43-05, 2005.

[17] ASCE/SEI Standard 4-16, Seismic Analysis of Safety-Related Nuclear Structures American Society of Civil Engineers, Reston, Fla, USA, 2017.

[18] D. Wang, C. Zhuang, and Y. Zhang, "Seismic response characteristics of base-isolated AP1000 nuclear shield building subjected to beyond-design basis earthquake shaking," Nuclear Engineering and Technology, vol. 50, pp. 170-180, 2018.

[19] M. Forni, A. Poggianti, F. Bianchi et al., "Seismic isolation of the IRIS nuclear plant," in Proceedings of the ASME Pressure Vessels and Piping Conference (PVP '09), pp. 289-296, Prague, Czech Republic, July 2009.

[20] IAEA, Innovative Small and Medium Sized Reactors: Design Features, Safety Approaches and R\&amp;D Trends, IAEATECDOC-1451, Vienna, 2005.

[21] M. D. Carelli, L. E. Conway, L. Oriani et al., "The design and safety features of the IRIS reactor," Nuclear Engineering and Design, vol. 230, no. 1-3, pp. 151-167, 2004.

[22] R. Lo Frano, G. Pugliese, and G. Forasassi, "Preliminary seismic analysis of an innovative near term reactor: Methodology and 
application," Nuclear Engineering and Design, vol. 240, no. 6, pp. 1671-1678, 2010.

[23] R. Lo Frano and G. Forasassi, "Isolation systems influence in the seismic loading propagation analysis applied to an innovative near term reactor," Nuclear Engineering and Design, vol. 240, no. 10, pp. 3539-3549, 2010.

[24] MSC.Software, MSC@MARC user guide, 2010.

[25] T. Kubo, T. Yamamoto, K. Sato, M. Jimbo, T. Imaoka, and Y. Umeki, "A seismic design of nuclear reactor building structures applying seismic isolation system in a high seismicity region -a feasibility case study in Japan-," Nuclear Engineering and Technology, vol. 46, no. 5, pp. 581-594, 2014.

[26] US NRC, R.G. 1.60, Design response spectra for seismic design of nuclear power plants, Rev. 1, 2010.

[27] C. G. Koh and J. M. Kelly, "A simple mechanical model for elastomeric bearings used in base isolation," International Journal of Mechanical Sciences, vol. 30, no. 12, pp. 933-943, 1988.

[28] S. Marzano, "A one-dimensional model for finite deformations of multilayered rubber bearings," International Journal of Solids and Structures, vol. 31, no. 15, pp. 2121-2138, 1994.

[29] R. Lo Frano and G. Forasassi, "Evaluation of Instability of Laminated Rubber Bearings under Dynamic Loading," in Proceedings of the ICAPP, San Diego, Calif, USA, June 2010. 

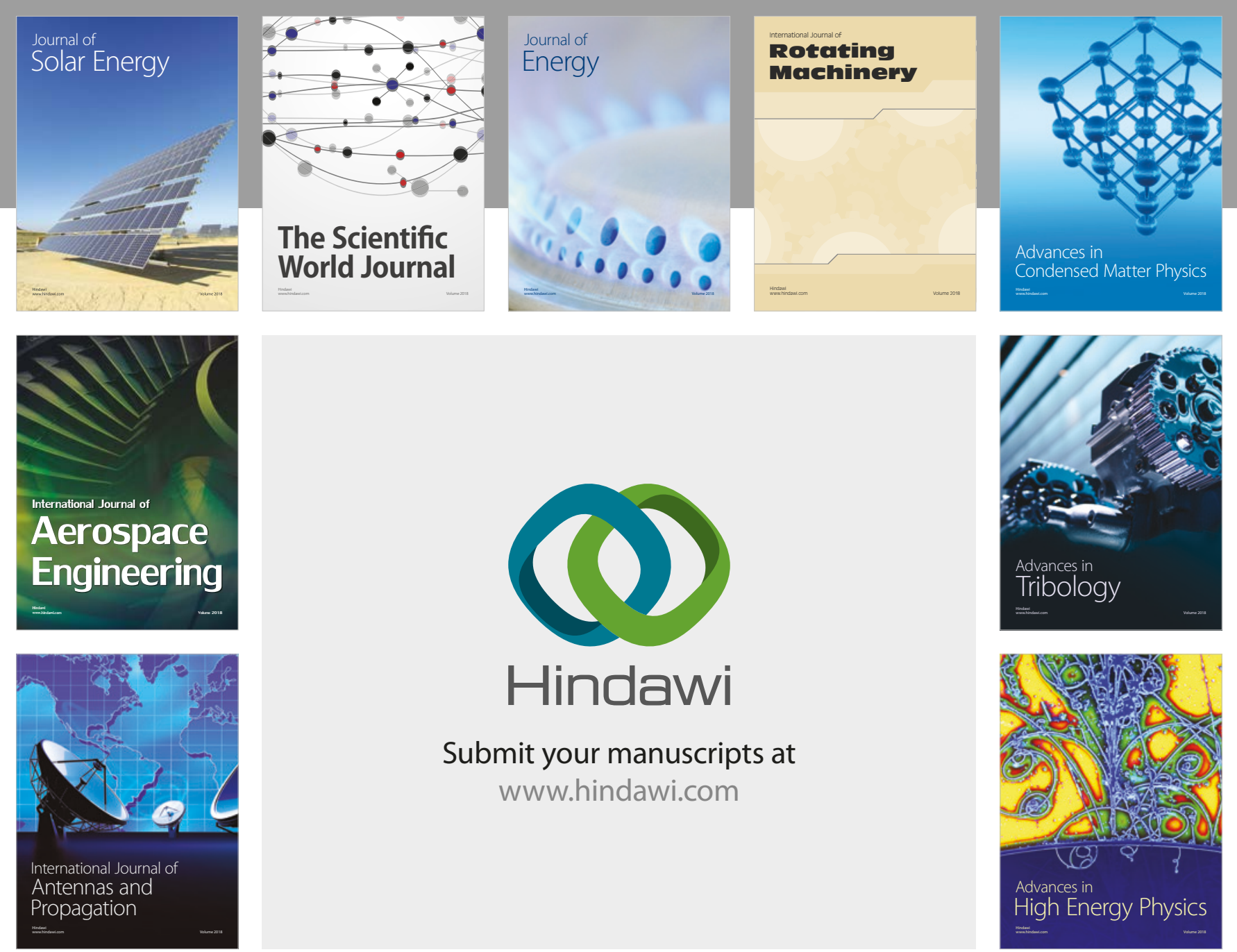

Submit your manuscripts at

www.hindawi.com
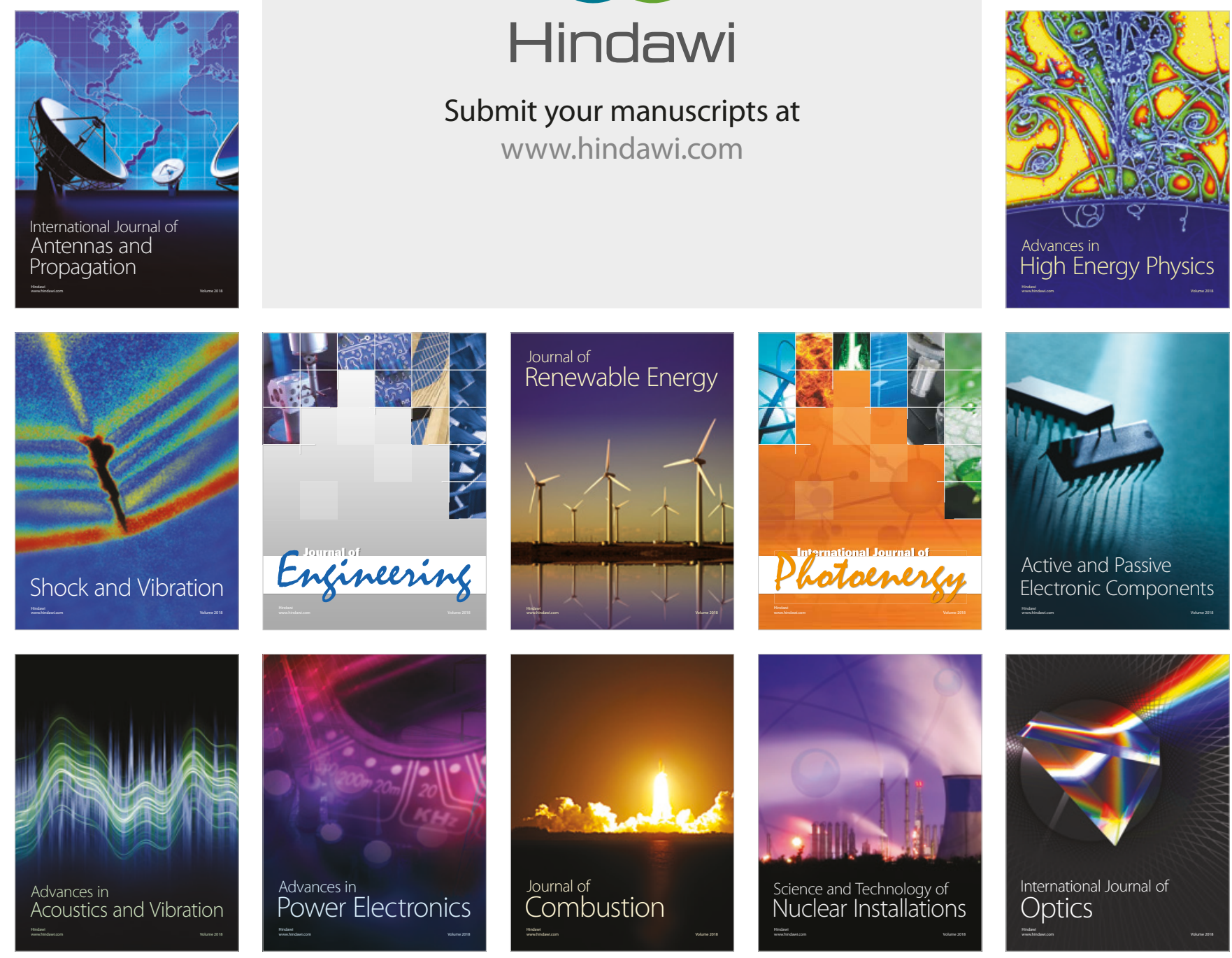